\title{
Evidence based medicine: a movement in crisis?
}

Trisha Greenhalgh and colleagues argue that, although evidence based medicine has had many benefits, it has also had some negative unintended consequences. They offer a preliminary agenda for the movement's renaissance, refocusing on providing useable evidence that can be combined with context and professional expertise so that individual patients get optimal treatment

\section{Trisha Greenhalgh dean for research impact ${ }^{1}$, Jeremy Howick senior research fellow ${ }^{2}$, Neal Maskrey professor of evidence informed decision making ${ }^{3}$, for the Evidence Based Medicine Renaissance Group}

${ }^{1}$ Barts and the London School of Medicine and Dentistry, London E1 2AB, UK; ${ }^{2}$ Centre for Evidence-Based Medicine, University of Oxford, Oxford OX2 6NW, UK; ${ }^{3}$ Keele University, Staffs ST5 5BG, UK

It is more than 20 years since the evidence based medicine working group announced a "new paradigm" for teaching and practising clinical medicine. ${ }^{1}$ Tradition, anecdote, and theoretical reasoning from basic sciences would be replaced by evidence from high quality randomised controlled trials and observational studies, in combination with clinical expertise and the needs and wishes of patients.

Evidence based medicine quickly became an energetic intellectual community committed to making clinical practice more scientific and empirically grounded and thereby achieving safer, more consistent, and more cost effective care. ${ }^{2}$

Achievements included establishing the Cochrane Collaboration to collate and summarise evidence from clinical trials; ${ }^{3}$ setting methodological and publication standards for primary and secondary research $;{ }^{4}$ building national and international infrastructures for developing and updating clinical practice guidelines, ${ }^{5}$ developing resources and courses for teaching critical appraisal $;{ }^{6}$ and building the knowledge base for implementation and knowledge translation. ${ }^{7}$

From the outset, critics were concerned that the emphasis on experimental evidence could devalue basic sciences and the tacit knowledge that accumulates with clinical experience; they also questioned whether findings from average results in clinical studies could inform decisions about real patients, who seldom fit the textbook description of disease and differ from those included in research trials. ${ }^{8}$ But others argued that evidence based medicine, if practised knowledgably and compassionately, could accommodate basic scientific principles, the subtleties of clinical judgment, and the patient's clinical and personal idiosyncrasies. $^{1}$
Two decades of enthusiasm and funding have produced numerous successes for evidence based medicine. An early example was the British Thoracic Society's 1990 asthma guidelines, developed through consensus but based on a combination of randomised trials and observational studies. ${ }^{9}$ Subsequently, the use of personal care plans and step wise prescription of inhaled steroids for asthma increased, ${ }^{10}$ and morbidity and mortality fell. ${ }^{11}$ More recently, uptake of the UK National Institute for Health and Care Excellence guidelines for prevention of venous thromboembolism after surgery has produced significant reductions in thromboembolic complications. ${ }^{12}$

Despite these and many other successes, wide variation in implementing evidence based practice remains a problem. For example, the incidence of arthroscopic washout of the knee joint, whose benefits are unproved except when there is a known loose body, varies from 3 to 48 per 100000 in England. ${ }^{13}$ More fundamentally, many who support evidence based medicine in principle have argued that the movement is now facing a serious crisis (box 1). ${ }^{14}{ }^{15}$ Below we set out the problems and suggest some solutions.

\section{Distortion of the evidence based brand}

The first problem is that the evidence based "quality mark" has been misappropriated and distorted by vested interests. In particular, the drug and medical devices industries increasingly set the research agenda. They define what counts as disease (for example, female sexual arousal disorder, treatable with sildenafil $^{16}$ and male baldness, treatable with finasteride ${ }^{17}$ ) and predisease "risk states" (such as low bone density, treatable with alendronate). ${ }^{18}$ They also decide which tests and treatments will 


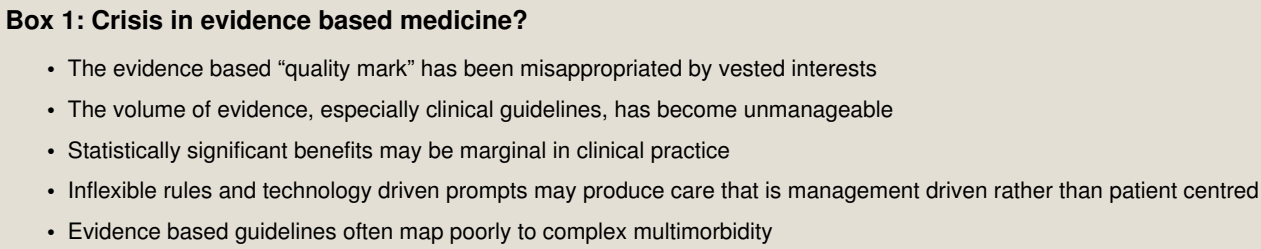

be compared in empirical studies and choose (often surrogate) outcome measures for establishing "efficacy.","

Furthermore, by overpowering trials to ensure that small differences will be statistically significant, setting inclusion criteria to select those most likely to respond to treatment, manipulating the dose of both intervention and control drugs, using surrogate endpoints, and selectively publishing positive studies, industry may manage to publish its outputs as "unbiased" studies in leading peer reviewed journals. ${ }^{20}$ Use of these kinds of tactic in studies of psychiatric drugs sponsored by their respective manufacturers enabled them to show that drug A outperformed drug B, which outperformed drug C, which in turn outperformed drug A. ${ }^{21}$ One review of industry sponsored trials of antidepressants showed that 37 of 38 with positive findings, but only 14 of 36 with negative findings, were published. ${ }^{22}$

Evidence based medicine's quality checklists and risk of bias tools may be unable to detect the increasingly subtle biases in industry sponsored studies. ${ }^{23}$ Some so called evidence based policies (such as dementia case finding for the over $75 \mathrm{~s}$ and universal health checks for the over 40s in the UK) seem to be based largely on political conviction. ${ }^{24}$ Critics have condemned the role of the drug industry in influencing the policy makers who introduced them. ${ }^{26}$

\section{Too much evidence}

The second aspect of evidence based medicine's crisis (and yet, ironically, also a measure of its success) is the sheer volume of evidence available. In particular, the number of clinical guidelines is now both unmanageable and unfathomable. One 2005 audit of a 24 hour medical take in an acute hospital, for example, included 18 patients with 44 diagnoses and identified 3679 pages of national guidelines (an estimated 122 hours of reading) relevant to their immediate care. ${ }^{27}$

\section{Marginal gains and a shift from disease to risk}

Evidence based medicine is, increasingly, a science of marginal gains-since the low hanging fruit (interventions that promise big improvements) for many conditions were picked long ago. After the early big gains of highly active antiretroviral therapy for $\mathrm{HIV}^{28}$ and triple therapy for Helicobacter pylori positive peptic ulcer, ${ }^{29}$ contemporary research questions focus on the marginal gains of whether these drug combinations should be given in series or in parallel and how to increase the proportion of patients who take their complex medication regimen as directed. ${ }^{30} 31$

Large trials designed to achieve marginal gains in a near saturated therapeutic field typically overestimate potential benefits (because trial samples are unrepresentative and, if the trial is overpowered, effects may be statistically but not clinically significant) and underestimate harms (because adverse events tend to be underdetected or underreported). The 74 year old who is put on a high dose statin because the clinician applies a fragment of a guideline uncritically and who, as a result, develops muscle pains that interfere with her hobbies and ability to exercise, is a good example of the evidence based tail wagging the clinical dog. In such scenarios, the focus of clinical care shifts insidiously from the patient (this 74 year old woman) to the population subgroup (women aged 70 to 75 ) and from ends (what is the goal of investigation or treatment in this patient?) to means (how can we ensure that everyone in a defined denominator population is taking statins?).

As the examples above show, evidence based medicine has drifted in recent years from investigating and managing established disease to detecting and intervening in non-diseases. Risk assessment using "evidence based" scores and algorithms (for heart disease, diabetes, cancer, and osteoporosis, for example) now occurs on an industrial scale, with scant attention to the opportunity costs or unintended human and financial consequences. ${ }^{26}$

\section{Overemphasis on following algorithmic rules}

Well intentioned efforts to automate use of evidence through computerised decision support systems, structured templates, and point of care prompts can crowd out the local, individualised, and patient initiated elements of the clinical consultation. ${ }^{8}$ For example, when a clinician is following a template driven diabetes check-up, serious non-diabetes related symptoms that the patient mentions in passing may not by documented or acted on. ${ }^{32}$ Inexperienced clinicians may (partly through fear of litigation) engage mechanically and defensively with decision support technologies, stifling the development of a more nuanced clinical expertise that embraces accumulated practical experience, tolerance of uncertainty, and the ability to apply practical and ethical judgment in a unique case. ${ }^{33}$

Templates and point of care prompts also contribute to the creeping managerialism and politicisation of clinical practice. ${ }^{8}$ As Harrison and Checkland observe: "As the language of EBM becomes ever more embedded in medical practice, and as bureaucratic rules become the accepted way to implement 'the best' evidence, its requirements for evidence are quietly attenuated in favour of an emphasis on rules." 34

For example, the Quality and Outcomes Framework (QOF) in UK general practice is incentivised by financial "quality points" and administered largely by non-clinical staff who generate these points by recalling patients for structured reviews and checks. QOF has been associated with significant improvements in blood pressure control, especially in deprived populations. ${ }^{35}$ But its downside is an audit driven, technocratic exercise in which few patients are offered personalised shared decision making with a senior clinician before having the recommended tests and treatments, and in which clinical consultations are continually interrupted by pop-up point of care prompts. ${ }^{32} 36$ 


\section{Poor fit for multimorbidity}

Finally, as the population ages and the prevalence of chronic degenerative diseases increases, the patient with a single condition that maps unproblematically to a single evidence based guideline is becoming a rarity. Even when primary studies were designed to include participants with multiple conditions, applying their findings to patients with particular comorbidities remains problematic. Multimorbidity (a single condition only in name) affects every person differently and seems to defy efforts to produce or apply objective scores, metrics, interventions, or guidelines. ${ }^{37}$ Increasingly, the evidence based management of one disease or risk state may cause or exacerbate another-most commonly through the perils of polypharmacy in the older patient. ${ }^{38}$

\section{Return to real evidence based medicine}

To address the above concerns, we believe it is time to launch a campaign for real evidence based medicine (box 2).

\section{Individualised for the patient}

Real evidence based medicine has the care of individual patients as its top priority, asking, "what is the best course of action for this patient, in these circumstances, at this point in their illness or condition?" 39 It consciously and reflexively refuses to let process (doing tests, prescribing medicines) dominate outcomes (the agreed goal of management in an individual case). It engages with an ethical and existential agenda (how should we live? when should we accept death?) and with that goal in mind, carefully distinguishes between whether to investigate, treat, or screen and how to do so. ${ }^{40}$

To support such an approach, evidence must be individualised for the patient. This requires that research findings be expressed in ways that most people will understand (such as the number needed to treat, number needed to harm, and number needed to screen $^{41}$ ) and that practitioners, together with their patients, are free to make appropriate care decisions that may not match what "best (average) evidence" seems to suggest.

Importantly, real shared decision making is not the same as taking the patient through a series of if-then decision options. Rather, it involves finding out what matters to the patient-what is at stake for them-and making judicious use of professional knowledge and status (to what extent, and in what ways, does this person want to be "empowered"?) and introducing research evidence in a way that informs a dialogue about what best to do, how, and why. This is a simple concept but by no means easy to deliver. Tools that contain quantitative estimates of risk and benefit are needed, but they must be designed to support conversations not climb probability trees.

\section{Judgment not rules}

Real evidence based medicine is not bound by rules. The Dreyfus brothers have described five levels of learning, beginning with the novice who learns the basic rules and applies them mechanically with no attention to context. ${ }^{42}$ The next two stages involve increasing depth of knowledge and sensitivity to context when applying rules. In the fourth and fifth stages, rule following gives way to expert judgments, characterised by rapid, intuitive reasoning informed by imagination, common sense, and judiciously selected research evidence and other rules.

In clinical diagnosis, for example, the novice clinician works methodically and slowly through a long and standardised history, exhaustive physical examination, and (often numerous) diagnostic tests. ${ }^{43}$ The expert, in contrast, makes a rapid initial differential diagnosis through intuition, then uses a more selective history, examination, and set of tests to rule in or rule out particular possibilities. To equate "quality" in clinical care with strict adherence to guidelines or protocols, however robust these rules may be, is to overlook the evidence on the more sophisticated process of advanced expertise.

\section{Aligned with professional, relationship based care}

Real evidence based medicine builds (ideally) on a strong interpersonal relationship between patient and clinician. It values continuity of care and empathetic listening, especially for people who are seriously and incurably sick. ${ }^{44}$ Research evidence may still be key to making the right decision-but it does not determine that decision. Clinicians may provide information, but they are also trained to make ethical and technical judgments, and they hold a socially recognised role to care, comfort, and bear witness to suffering. ${ }^{45}$ The challenges of self management in severe chronic illness, for example, are not merely about making treatment choices but about the practical and emotional work of implementing those choices. ${ }^{46}$ As serious illness is lived, evidence based guidelines may become irrelevant, absurd, or even harmful (most obviously, in terminal illness).

\section{Public health dimension}

Although we have focused on individual clinical care, there is also an important evidence base relating to population level interventions aimed at improving public health (such as pricing and labelling of consumables, fluoridation of water, and sex education). These are often complex, multifaceted programmes with important ethical and practical dimensions, but the same principles apply as in clinical care. Success of interventions depends on local feasibility, acceptability, and fit with context - and hence on informed, shared decision making with and by local communities, using summaries and visualisations of population level metrics. ${ }^{47}$

\section{Delivering real evidence based medicine}

To deliver real evidence based medicine, the movement's stakeholders must be proactive and persistent. Patients (for whose care the movement exists) must demand better evidence, better presented, better explained, and applied in a more personalised way with sensitivity to context and individual goals. ${ }^{48}$ There are already some models of good practice here. In arthritis, for example, patient advocacy groups that emphasise the importance of experiential evidence and patient centred strategies have existed for over 30 years and have influenced the choice of outcome measures used in comparative effectiveness studies. ${ }^{49}$ Patient input has refocused several NICE guidelines (for example, on psoriasis). ${ }^{50}$

Third sector advisory and advocacy groups such as the UK's Consumer Association (www.which.co.uk), Picker Institute (www.pickereurope.org), and Sense About Science (www. senseaboutscience.org) have a crucial role in educating citizens and contributing to public debate about the use and abuse of evidence. The James Lind Alliance (www.lindalliance.org) brings patients, carers, and clinicians together to prioritise research questions. Such groups must remain, as far as possible, independent of vested interests and aware of the distorting influence of tied funding. 


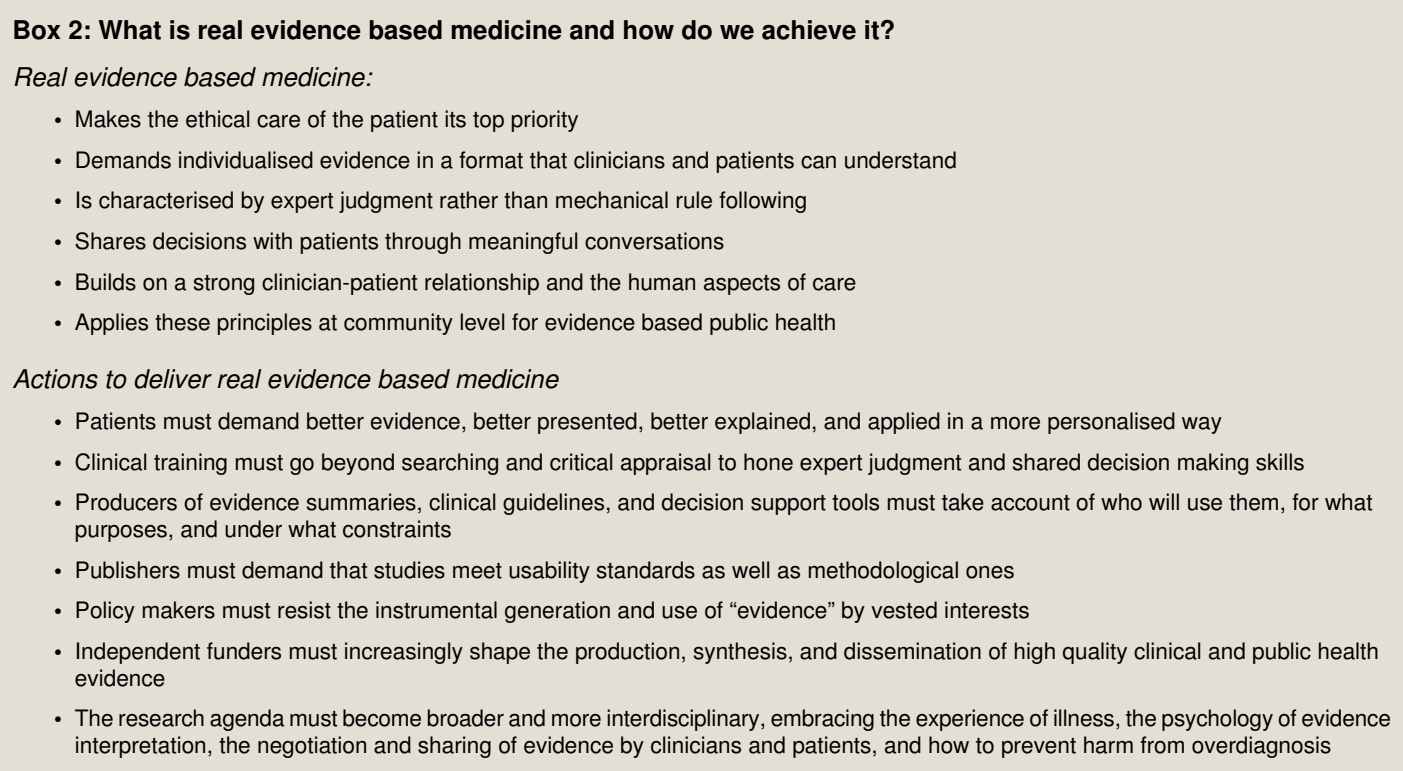

\section{Training must be reoriented from rule following}

Critical appraisal skills-including basic numeracy, electronic database searching, and the ability systematically to ask questions of a research study-are prerequisites for competence in evidence based medicine. ${ }^{6}$ But clinicians need to be able to apply them to real case examples. ${ }^{51}$

Too often, teaching resources use schematic, fictionalised vignettes in which the sick patient is reduced to narrative "factoids" that can populate a decision tree or a score sheet in an objective structured clinical examination. Rather than focus on these tidy textbook cases, once they have learnt some basic rules and gained some experience, students should be encouraged to try intuitive reasoning in the clinic and at the bedside, and then use formal evidence based methods to check, explain, and communicate diagnoses and decisions. ${ }^{43}$ They must also be taught how to share both evidence and uncertainty with patients using appropriate decision aids ${ }^{52}$ and adapt their approach to individual needs, circumstances, and preferences. ${ }^{39}$

Likewise, there is a strong argument for extending the continuing medical education curriculum beyond "evidence updates." Peer observation and review, reflective case discussion in small groups (with input from patients who want to articulate their experiences, choices, and priorities) and ongoing conversations with fellow professionals can help hone and maintain the ability to manage the challenges of applying evidence based medicine in the real world. ${ }^{53}$ The linking together of educational theory, cognitive psychology, information mastery, and implementation science into a coherent approach that supports front line decision making with patients ${ }^{54}$ is rarely taught in practice.

\section{Evidence must be usable as well as robust}

Another precondition for real evidence based medicine is that those who produce and summarise research evidence must attend more closely to the needs of those who might use it. Lengthy and expensive reviews that are "methodologically robust" but unusable in practice often fail to inform, inspire, or influence..$^{55}$ A recent systematic review of diabetes risk scores revealed that the authors of most studies were primarily concerned with the intellectual concept of improving the predictive value of the score but had given little or no thought to how their score might be used, by whom, or for what-nor what the implications would be for real people who would be designated "at risk" by the score. $^{56}$

Evidence users include clinicians and patients of varying statistical literacy, many of whom have limited time or inclination for the small print. ${ }^{41}$ Different approaches such as brief, plain language summaries for the non-expert (as offered by NICE), visualisations,${ }^{57}$ infographics,${ }^{52}$ option grids,${ }^{58}$ and other decision aids ${ }^{59}$ should be routinely offered and widely used. Yet currently, only a fraction of the available evidence is presented in usable form, and few clinicians are aware that such usable shared decision aids exist.

\section{Publishers must raise the bar}

This raises an imperative for publishing standards. Just as journal editors shifted the expression of probability from potentially misleading $P$ values to more meaningful confidence intervals by requiring them in publication standards,${ }^{60}$ so they should now raise the bar for authors to improve the usability of evidence, and especially to require that research findings are presented in a way that informs individualised conversations.

Given that real evidence based medicine is as much about when to ignore or over-ride guidelines as how to follow them, those who write guidelines should flag up the need for judgment and informed, shared decision making. The American College of Cardiology recently published new cholesterol guidelines $;{ }^{61}$ $J A M A$ followed with a pragmatic, patient focused article on how to apply this guideline and when to consider ignoring it, including an online visualisation tool to support conversations with patients. ${ }^{62}$ As the authors commented, "the target for performance measures is not the percentage of patients who.. . are prescribed statins, but the proportion of eligible patients who participate in shared decision making about statin use." Their approach deserves to be emulated widely.

\section{Research must transcend conflicts of interest}

To support real evidence based medicine, and in particular to reassure policy makers, clinicians, and the public that research and the guidance derived from it can be trusted, ${ }^{63}$ the infrastructure for research and guideline development must show the highest standards of probity. Independent funding of national bodies for medical research is crucial. 


\section{Broader, more imaginative research is needed}

The research agenda for real evidence based medicine is much broader than critical appraisal and draws on a wider range of underpinning disciplines. For example, it should include the study of the patient's experience of illness and the real life clinical encounter for different conditions and in different circumstances. The field would be enriched, for example, by qualitative research to elucidate the logic of care-that is, the numerous elements of good illness management that are complementary to the application of research evidence. ${ }^{64}$

We need to gain a better understanding (perhaps beginning with a synthesis of the cognitive psychology literature) of how clinicians and patients find, interpret, and evaluate evidence from research studies, and how (and if) these processes feed into clinical communication, exploration of diagnostic options, and shared decision making. ${ }^{54}$ Deeper study is also needed into the less algorithmic components of clinical method such as intuition and heuristic reasoning, and how evidence may be incorporated into such reasoning. ${ }^{43}$

In relation to producing usable evidence, we need to identify how to balance gold standard systematic reviews with pragmatic, rapid reviews that gain in timeliness and accessibility what they lose in depth and detail. ${ }^{65}$ In the same vein, we need research on how and in what circumstances to trade detail for brevity in developing guidelines. We need to develop decision aids that support clinicians and patients to clarify the goals of care, raise and answer questions about the quality and completeness of evidence, and understand and contextualise estimates of benefit and harm. We also need to improve both the usefulness and ease of use of these and other evidence based tools (models, scores, algorithms, and so on) including the intellectual, social, and temporal demands they make on users and the resource implications for the healthcare organisation and system.

In the educational field, it is time we extended the evidence base for integrated curriculums that promote reflection and case discussion alongside the application of evidence. ${ }^{66}$ Discussions on how to interpret and apply evidence to real cases, and the sharing of collective knowledge and expertise in the form of "mindlines" among clinicians ${ }^{53}$ or within illness communities ${ }^{67}$ may provide useful data sources for such studies. It is by studying these more sophisticated forms of knowing that we are likely to determine how best to produce expert clinicians and expert patients, and to prevent the harms that arise from overdiagnosis, overtreatment, and overscreening. ${ }^{33}$

In relation to effectiveness, we need greater attention to postmarketing research in day to day hospital and primary care settings to confirm that subsequent experience replicates the results of licensing trials. This will allow gold standard tests and their cut-off points for ruling out diagnoses and treatments to be revised to minimise overdiagnosis or underdiagnosis. ${ }^{43}$

Finally, in relation to the collective effort to prevent the misappropriation of the evidence based quality mark, a key research priority remains the study of hidden biases in sponsored research-for example, by refining the statistical techniques for challenging findings that appear too good to be true.

\section{Conclusion}

Much progress has been made and lives have been saved through the systematic collation, synthesis, and application of high quality empirical evidence. However, evidence based medicine has not resolved the problems it set out to address (especially evidence biases and the hidden hand of vested interests), which have become subtler and harder to detect. Furthermore, contemporary healthcare's complex economic, political, technological and commercial context has tended to steer the evidence based agenda towards populations, statistics, risk, and spurious certainty. Despite lip service to shared decision making, patients can be left confused and even tyrannised when their clinical management is inappropriately driven by algorithmic protocols, top-down directives and population targets.

Such problems have led some to argue for the rejection of evidence based medicine as a failed model. Instead we argue for a return to the movement's founding principles-to individualise evidence and share decisions through meaningful conversations in the context of a humanistic and professional clinician-patient relationship (box 2). To deliver this agenda, evidence based medicine's many stakeholders-patients, clinicians, educators, producers and publishers of evidence, policy makers, research funders, and researchers from a range of academic disciplines-must work together. Many of the ideas in this paper are not new, and a number of cross sector campaigns with similar goals have already begun (box 3). We hope that our call for a campaign for real evidence based medicine will open up debate and invite readers to contribute (for example, by posting rapid responses on bmj.com).

We thank Ruth Davis and Sarah Hardy for administrative support. The workshop was funded by a National Institute for Health Research senior investigator award for TG and by the Oxford Centre for Evidence Based Medicine. We also thank Bernard Higgins for advice on sections of the manuscript and Michael Rawlins and BMJ editors for helpful comments.

Contributors and sources: Other members of the Evidence Based Medicine Renaissance Group are: Jon Brassey, Druin Burch, Martin Burton, Hasok Chang, Paul Glasziou, Iona Heath, Carl Heneghan, Michael P Kelly, Richard Lehman, Huw Llewelyn, Margaret McCartney, Ruairidh Milne, and Des Spence. This essay is partly the product of a workshop held at Kellogg College, Oxford, on 13-14 January 2014 and organised collaboratively by the Centre for Evidence Based Medicine, University of Oxford and the Centre for Primary Care and Public Health, Barts and the London School of Medicine and Dentistry. TG, in correspondence with $\mathrm{CH}$, conceptualised the idea for a reappraisal and renaissance of evidence based medicine and developed the plan to hold a workshop to progress this idea. TG and JH facilitated the workshop. All authors attended the workshop and contributed to the development of key themes for the paper. TG wrote the first draft of the paper and refined it with important intellectual contribution from $\mathrm{JH}$ and NM. All authors provided some feedback on earlier drafts of the paper and approved the final manuscript.

Competing interests: All authors have read and understood BMJ policy on declaration of interests and declare the following interests: NM and MK have senior roles in the National Institute for Health and Care Excellence; RM is employed by, and TG and JH's salaries are part funded by, the National Institute for Health Research; MB is director of the UK Cochrane Centre. JB is a director and shareholder in the TRIP database, which offers a rapid search service. $R L$ is a founder member, and TG a member, of the AllTrials campaign. IH is chairing the scientific committee for the preventing overdiagnosis conference in September 2014, and $P G$ and $H L$ have also been active in the preventing overdiagnosis campaign. $\mathrm{RL}$ is currently a consultant to the Yale Open Data Access project, which receives funding from Johnson and Johnson to develop methods to promote clinical trial data sharing; the project has also received funding from Medtronic.

Provenance and peer review: Not commissioned; externally peer reviewed.

Evidence Based Medicine Working Group. Evidence based medicine. A new approach to teaching the practice of medicine. JAMA 1992;268:2420-5.

2 Pope C. Resisting evidence: the study of evidence-based medicine as a contemporary social movement. Health 2003;7:267-82 


\section{Box 3: Campaigns aligned with real evidence based medicine}

Too much medicine - A rapidly growing movement, led jointly by clinicians, academics and patients, aims to reduce harm from overdiagnosis, overscreening, and overtreatment. ${ }^{2633}$ The second of what will hopefully be an annual "preventing overdiagnosis" conference will be held in Oxford in September 2014 (www.preventingoverdiagnosis.net)

All trials (www.alltrials.net) - an international initiative to ensure that all clinical trials are registered at inception and no findings are withheld from publication

Reducing waste and increasing value in medical research (www.thelancet.com/series/research)—A recent Lancet series highlighting the waste and loss of value caused by research that addresses the wrong questions, uses inappropriate study designs; is weighed down by bureaucracy, or is so badly or inaccessibly reported that practitioners and policymakers simply cannot apply it

Improving publishing standards (www.icmje.org/urm_main.html ) —A campaign by the International Committee of Medical Journal Editors to improve the quality and transparency of medical publishing by discouraging ghost-writing and raising the standards for declarations of conflicts of interest

Integrated medical education-Campaign to strengthen the integration of the different components of the curriculum by developing bedside clinical skills, understanding and applying research evidence, and reflecting and deliberating about complex cases ${ }^{6869}$

3 Levin A. The Cochrane Collaboration. Ann Intern Med 2001:135:309-12.

Simera I, Moher D, Hirst A, Hoey J, Schulz KF, Altman D. Transparent and accurate reporting increases reliability, utility, and impact of your research: reporting guidelines and the EQUATOR Network. BMC Med 2010;8:24

5 Hill J, Bullock I, Alderson P. A summary of the methods that the National Clinical Guideline Centre uses to produce clinical guidelines for the National Institute for Health and Clinical Excellence. Ann Intern Med 2011;154:752-7.

6 Horsley T, Hyde C, Santesso N, Parkes J, Milne R, Stewart R. Teaching critical appraisal skills in healthcare settings. Cochrane Database Syst Rev 2011;11: CD001270.

7 McCormack L, Sheridan S, Lewis M, Boudewyns V, Melvin CL, Kistler C. Communication and dissemination strategies to facilitate the use of health-related evidence. Evidence Reports/Technology Assessments No 213. US Agency for Healthcare Research and Quality, 2013.

8 Timmermans S, Berg M. The gold standard: the challenge of evidence-based medicine and standardization in health care. Temple University Press, 2003.

9 British Thoracic Society. Guidelines for management of asthma in adults: I. Chronic persistent asthma. BMJ 1990;301:651-3.

10 Majeed A, Ferguson J, Field J. Prescribing of beta-2 agonists and inhaled steroids in England: trends between 1992 and 1998, and association with material deprivation, chronic illness and asthma mortality rates. J Pub Health Med 1999;21:395-400.

11 Kelly MP, Capewell S. Relative contributions of changes in risk factors and treatment to the reduction in coronary heart disease mortality. Health Development Agency, 2004.

12 Lau BD, Haut ER. Practices to prevent venous thromboembolism: a brief review. BM Qual Safety 2014;23:187-95.

13 Gray JAM. NHS Atlas of variation in healthcare. 2011. www.rightcare.nhs.uk/index.php/ atlas/atlas-of-variation-2011/.

4 loannidis JP. Why most published research findings are false. PLoS Med 2005;2:e124.

5 Greenhalgh T. Why do we always end up here? Evidence-based medicine's conceptual cul-de-sacs and some off-road alternative routes. J Primary Health Care 2012:4:92-7.

16 Basson R, Mclnnes R, Smith MD, Hodgson G, Koppiker N. Efficacy and safety of sildenafil citrate in women with sexual dysfunction associated with female sexual arousal disorder. $J$ Women's Health Gender Based Med 2002;11:367-77.

17 Leyden J, Dunlap F, Miller B, Winters P, Lebwohl M, Hecker D. Finasteride in the treatment of men with frontal male pattern hair loss. J Am Acad Dermatol 1999;40:930-7.

18 Bone HG, Greenspan SL, McKeever C, Bell N, Davidson M, Downs RW.Alendronate and estrogen effects in postmenopausal women with low bone mineral density 1 . J Clin Endocrinol Metab 2000;85:720-6.

19 Cohen D. FDA official: "clinical trial system is broken." BMJ 2013;347:66980.

20 Every-Palmer S, Howick J. How evidence-based medicine is failing due to biased trials and selective publication. J Eval Clin Pract 2014 May 12. [Epub ahead of print.]

21 Heres S, Davis J, Maino K, et al. Why olanzapine beats risperidone, risperidone beats quetiapine, and quetiapine beats olanzapine: an exploratory analysis of head-to-head comparison studies of second-generation antipsychotics. Am J Psychiatry 2006;163:185-94

22 Turner EH, Matthews AM, Linardatos E, Tell R, Rosenthal R. Selective publication of antidepressant trials and its influence on apparent efficacy. N Engl J Med 2008;358:252-60.

23 Higgins JP, Altman DG, Gøtzsche PC, Jüni P, Moher D, Oxman AD, et al. The Cochrane Collaboration's tool for assessing risk of bias in randomised trials. BMJ 2011:343.d5928.

24 Le Couteur DG, Doust J, Creasey H, Brayne C. Political drive to screen for pre-dementia: not evidence based and ignores the harms of diagnosis. BMJ 2013;347:f5125.

25 Krogsbøll LT, Jørgensen KJ, Grønhøj Larsen C, Larsen C, Gøtzsche PC.. General health checks in adults for reducing morbidity and mortality from disease. Cochrane Database Syst Rev 2012;10:CD009009.

26 Moynihan R, Doust J, Henry D. Preventing overdiagnosis: how to stop harming the healthy. BMJ 2012;344:e3502.

27 Allen D, Harkins K. Too much guidance? Lancet 2005;365:1768.

28 Palella FJ Jr, Delaney KM, Moorman AC, Loveless MO, Fuhrer J, Satten GA, et al. Declining morbidity and mortality among patients with advanced human immunodeficiency virus infection. HIV Outpatient Study Investigators. N Engl J Med 1998;338:853-60.

29 NICE. Dysepsia: managing dyspepsia for adults in primary care (GC17). 2004. http:// guidance.nice.org.uk/CG17/Guidance/pdf/English.

30 Gatta L, Vakil NB, Scarpignato C, Fiorini G, Castelli V, Vaira D. Sequential therapy for eradication of Helicobacter pylori infection in adults: still far from the ideal treatment. a systematic review and meta-analysis. Gastroenterology 2013;144:S332.

31 Hart JE, Jeon CY, Ivers LC, Behlforouz HL, Caldas A, Drobac PC, et al. Effect of directly observed therapy for highly active antiretroviral therapy on virologic, immunologic, and adherence outcomes: a meta-analysis and systematic review. JAIDS 2010;54:167-79.

32 Swinglehurst D, Greenhalgh T, Roberts C. Computer templates in chronic disease management: ethnographic case study in general practice. BMJ Open 2012;2:e001754.

33 Glasziou P, Moynihan R, Richards T, Godlee F. Too much medicine; too little care. BMJ 2013;347:44247.

34 Harrison S, Checkland K. Evidence-based practice in UK health policy. Routledge, 2009.
35 Doran T, Fullwood C, Kontopantelis E, Reeves D. Effect of financial incentives on inequalities in the delivery of primary clinical care in England: analysis of clinical activity indicators for the quality and outcomes framework. Lancet 2008;372:728-36.

36 Gillam S. Expert commentary. Pay for performance in UK general practice- the ambiguous impact of the Quality and Outcomes Framework. 2011. www.qualitymeasures.ahrq.gov/ expert/expert-commentary.aspx?id=25658\&search=Primary \pm Health \pm Care \pm .

37 Huntley AL, Johnson R, Purdy S, Valderas JM, Salisbury C. Measures of multimorbidity and morbidity burden for use in primary care and community settings: a systematic review and guide. Ann Fam Med 2012;10:134-41.

38 Duerden M, Avery T, Payne R. Polypharmacy and medicines optimization: making it safe and sound. King's Fund, 2013

39 Montgomery K. How doctors think: clinical judgement and the practice of medicine. Oxford University Press, 2006.

40 McNutt R, Handler NM. How clinical guidelines fail both doctors and patients. Scientific American Blog Network, 22 November 2013. http://blogs.scientificamerican.com/guestblog/2013/11/22/how-clinical-guidelines-can-fail-both-doctors-and-patients/.

41 Gigerenzer G, Gaissmaier W, Kurz-Milcke E, Schwartz LM, Woloshin S. Helping doctors and patients make sense of health statistics. Psychol Sci Public Interest 2007;8:53-96.

42 Dreyfus HL, Dreyfus SE, Zadeh LA. Mind over machine: the power of human intuition and expertise in the era of the computer. IEEE Expert 1987;2:110-11.

43 Llewelyn H, Ang HA, Lewis D, Al-Abdullah A. Oxford Handbook of Clinical Diagnosis Oxford University Press, 2014

44 Frank AW. Just listening: narrative and deep illness. Families Systems Health 1998;16:197.

45 Schei E. Doctoring as leadership: the power to heal. Perspect Biol Med 2006:49:393-406.

46 Hinder S, Greenhalgh T. "This does my head in." Ethnographic study of self-management by people with diabetes. BMC Health Serv Res 2012;12:83.

47 Rosling H, Zhang Z. Health advocacy with Gapminder animated statistics. J Epidemiol Global Health 2011;1:11-4

48 Richards T, Montori VM, Godlee F, Lapsley P, Paul D. Let the patient revolution begin. BMJ 2013;346:f2614.

49 Gierisch JM, Myers ER, Schmit KM, McCrory DC, Coeytaux RR, Crowley MJ, et al. Prioritization of patient-centered comparative effectiveness research for osteoarthritis. Ann Intern Med 2014 May 13. [Epub ahead of print.]

50 National Institute for Health and Clinical Excellence. Psoriasis: the assessment and management of psoriasis. CG153 . NICE, 2012.

51 Green ML. Evidence-based medicine training in graduate medical education: past, present and future. J Eval Clin Pract 2000;6:121-38.

52 Spiegelhalter $\mathrm{D}$, Pearson $\mathrm{M}$, Short I. Visualizing uncertainty about the future. Science 2011;333:1393-400.

53 Gabbay J, May Al. Evidence based guidelines or collectively constructed "mindlines? Ethnographic study of knowledge management in primary care. BMJ 2004;329:1013.

54 Supporting adoption of evidence into practice. MeReC Bull 2011;22:2-7. www.npc.nhs. $\mathrm{uk} / \mathrm{merec} /$ therap/other/merec bulletin vol22 no2.php.

55 Lavis JN, Davies HT, Gruen RL, Walshe K, Farquhar CM. Working within and beyond the Cochrane Collaboration to make systematic reviews more useful to healthcare managers and policy makers. Healthcare Policy 2006;1:21-33.

56 Noble D, Mathur R, Dent T, Meads C, Greenhalgh T. Risk models and scores for type 2 diabetes: systematic review. BMJ 2011;343:d7163.

57 Garcia-Retamero R, Galesic M. Who profits from visual aids? Overcoming challenges in people's understanding of risks. Soc Sci Med 2010;70:1019-25.

58 Elwyn G, Lloyd A, Joseph-Williams N, Cording E, Thomson R, Durand MA, et al. Option grids: shared decision making made easier. Patient Educ Counsel 2013;90:207-12.

59 Volk R, Llewellyn-Thomas H, Stacey D, Elwyn, G. The International Patient Decision Aid Standards (IPDAS) Collaboration quality dimensions: theoretical rationales, current evidence, and emerging issues. BMC Med Inform Decision Making 2013:S1-14.

60 Gardner MJ, Altman DG. Confidence intervals rather than P values: estimation rather than hypothesis testing. BMJ 1986;292:746.

61 Goff DC, Lloyd-Jones DM, Bennett G, O'Donnell CJ, Coady S, Robinson J, et al. 2013 ACC/AHA guideline on the assessment of cardiovascular risk. J Am Coll Cardiol 2013 Nov 12. [Epub ahead of print.]

62 Montori VM, Brito JP, Ting HH. Patient-centered and practical application of new high cholesterol guidelines to prevent cardiovascular disease. JAMA 2014:311:465-6.

63 Lenzer J. Why we can't trust clinical guidelines. BMJ 2013;346:f3830.

64 Mol A. The logic of care: health and the problem of patient choice. Routledge, 2008.

65 Ganann R, Ciliska D, Thomas H. Expediting systematic reviews: methods and implications of rapid reviews. Implement Sci 2010;5:56.

66 West CP, Dyrbye LN, Rabatin JT, Call TG, Davidson JH, Multari A, et al. Intervention to promote physician well-being, job satisfaction, and professionalism: a randomized clinical trial. JAMA Intern Med 2014;174:527-33.

67 Eysenbach G, Powell J, Englesakis M, Rizo C, Stern A. Health related virtual communities and electronic support groups: systematic review of the effects of online peer to peer interactions. BMJ 2004;328:1166.

68 Chanchlani N, Godlee F. Educating tomorrow's doctors. BMJ 2012;344:e3689. 
69 Cooke M, Irby DM, O'Brien BC. Educating physicians: a call for reform of medical school and residency. Wiley, 2010.
Cite this as: BMJ 2014;348:g3725

C BMJ Publishing Group Ltd 2014 